\title{
O tratamento pré-colheita com aminoetoxivinilglicina ou ácido giberélico preserva a qualidade pós-colheita de ameixas 'Laetitia'
}

\author{
Cristiano André Steffens ( $\left.{ }^{* *}\right)$; Cassandro Vidal Talamini do Amarante ('); Ricardo Chechi ('); \\ Odimar Zanuzo Zanardi ('); Bruno Pansera Espindola ('); Ana Luiza Meneghini (') \\ (') Universidade do Estado de Santa Catarina, Centro de Ciências Agroveterinárias (CAV), Departamento de Agronomia, Av. Luiz de \\ Camões, 2090, Caixa Postal 281, 88520-000 Lages (SC).E-mail:steffens@cav.udesc.br (*) Autor correspondente. \\ amarante@cav.udesc.br; a6rc@cav.udesc.br; odimarzanardi@yahoo.com.br; a6bp@cav.udesc.br; analuizaalm@hotmail.com
}

Recebido: 5/mai./2010; Aceito: 25/mai./2010

\begin{abstract}
Resumo
O objetivo deste trabalho foi avaliar os efeitos do tratamento pré-colheita com aminoetoxivinilglicina (AVG; 0, 90, 120 mg $\left.\mathrm{L}^{-1}\right)$ e ácido giberélico $\left(\mathrm{GA}_{3} ; 0\right.$ e $\left.100 \mathrm{mg} \mathrm{L}^{-1}\right)$ sobre a qualidade de ameixas 'Laetitia' após o armazenamento refrigerado. A aplicação do AVG e do $\mathrm{GA}_{3}$ foi realizada, respectivamente, a sete e 28 dias antes do início da colheita comercial dos frutos. Os frutos foram armazenados em câmara frigorífica comercial durante 22 dias a $0,5{ }^{\circ} \mathrm{C}$ e $92 \%$ de umidade relativa (UR), mais cinco dias de exposição em condições não controladas de temperatura e UR ( $\left.23 \pm 5^{\circ} \mathrm{C} / 60 \pm 10 \%\right)$. Não foi observada interação entre o AVG e o GA $\mathrm{A}_{3}$ em todos os atributos de qualidade avaliados. $\mathrm{O}$ tratamento pré-colheita com $\mathrm{GA}$, ou com AVG proporcionou maiores valores de firmeza de polpa e retardou o incremento no teor de sólidos solúveis. O AVG retardou a evolução da coloração da epiderme e a incidência de podridões. O tratamento com $\mathrm{CA}_{3}$ causou maior acidez titulável. $\mathrm{O}$ efeito do incremento nas doses de AVG sobre a manutenção da consistência da polpa e da cor da epiderme e na redução de podridões foi linear.
\end{abstract}

Palavras-chave: Prunus salicina, reguladores de crescimento, etileno, amadurecimento.

\section{Preharvest spraying with aminoethoxyvinylglycine or gibberelic acid improves postharvest fruit quality of 'Laetitia' plums}

Abstract

This work was carried out to evaluate the effects of preharvest spraying of Japanese plum trees (Prunus salicina, cv. Laetitia)

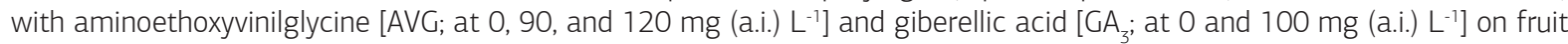
quality after cold storage. GA 3 and AVG were sprayed 28 and seven days before fruit harvesting, respectively. Fruit quality was assessed after 22 days of cold storage $\left(0.5^{\circ} \mathrm{C} / 92 \% \mathrm{RH}\right)$, followed by five days of shelf life $\left(23^{\circ} \mathrm{C} / 60 \% \mathrm{RH}\right)$. There was no interaction between AVG and GA for all fruit quality attributes. Preharvest spraying with $\mathrm{GA}_{3}$ and AVG increased flesh firmness, and delayed the increased of soluble solids content of the fruits. AVG delayed skin color evolution and reduced decay incidence. The treatment with $\mathrm{GA}_{3}$ caused high titratable acidity. There was a linear response to AVG doses considering the maintenance of flesh consistence and skin color, and on reduction of decay incidence.

Key words: Prunus salicina, growth regulators, ethylene, ripening. 


\section{INTRODUÇÃO}

A safra brasileira de ameixas é curta, compreendendo os meses de novembro a fevereiro, o que favorece a entrada de ameixas importadas para complementação da oferta sazonal. O armazenamento refrigerado da ameixa brasileira seria então uma alternativa viável para estender o período de oferta do produto nacional, mas ainda é pouco praticado. Além disso, a ameixa, devido ao metabolismo acentuado, apresenta período de armazenamento também reduzido, quando comparada a outros frutos de comportamento climatérico, como maçãs e peras (KADER, 2002), concentrando assim o período de comercialização (Brackmann et al., 2002). Desta forma, poucos dias de atraso na maturação desses frutos ou mesmo o próprio aumento no período de armazenamento poderiam causar incremento expressivo no preço de venda do produto e aumentar a receita por parte do produtor (BRACKMANN et al. 2002).

O uso da atmosfera controlada (AC) ou da atmosfera modificada (AM) associada à refrigeração melhora a manutenção da qualidade de frutos durante o armazenamento (STeffens et al., 2007). No entanto, além de não existirem informaçôes sobre as condiçốes ideais de armazenamento desta cultivar de ameixa em AC ou AM, a maioria dos produtores na Região Sul do Brasil não possuem essas tecnologias de armazenamento.

$\mathrm{Na}$ fruticultura, os reguladores de crescimento que inibem a síntese ou a ação do etileno vêm sendo utilizados para retardar a maturação e preservar a qualidade dos frutos durante o armazenamento, como é o caso da maçã (STEFfens et al., 2005a), caqui (Ferri et al., 2002; 2004) e pêssego (AMARANTE et al., 2005), sendo considerado como acessível aos produtores de ameixas e demais frutos de caroço (Amarante et al., 2005).

O composto aminoetoxivinilglicina (AVG) inibe a síntese do etileno e retarda todos os eventos fisiológicos que são estimulados por este fitormônio, dos quais muitos estão relacionados diretamente ao amadurecimento dos frutos (STEFfens et al., 2005a). Em maçãs, além de reduzir a queda pré-colheita e atrasar a maturação dos frutos, a aplicação de AVG permite melhor manutençấo da qualidade dos frutos durante o armazenamento (STefFens et al., 2005a,b). Nesse contexto, frutos tratados com AVG em pré-colheita são mais verdes, com maior firmeza de polpa, acidez titulável e sólidos solúveis, além da menor incidência de podridōes e de distúrbios fisiológicos (Steffens et al., 2005a). Em ameixas, tem sido verificado que o AVG retarda a maturação dos frutos e o efeito do mesmo é cultivardependente (Petri et al., 2005).

Outro regulador de crescimento que tem demonstrado efeito sobre o controle da maturação e do amadurecimento dos frutos é o ácido giberélico $\left(\mathrm{GA}_{3}\right)$ (Amarante et al., 2005). Alguns trabalhos têm demonstrado que o $\mathrm{GA}_{3}$ retarda a maturação de caqui, reduzindo o desverdecimento dos frutos e proporcionando maiores valores de firmeza de polpa, acidez titulável e massa dos frutos, além de reduzir a ocorrência de podridôes (Ferri et al., 2002; 2004). A aplicaçáo de giberelina pode inibir, parcialmente, a ação do etileno, retardando o amolecimento, a perda de clorofila e o acúmulo de carotenóides (BrackMAnN et al., 2002). Esses efeitos permitem retardar a colheita e prolongar o tempo de armazenamento dos frutos (STEFFENs et al., 2009). A degradação da clorofila, a constante síntese de pigmentos amarelados e/ou avermelhados e a reduçáo da firmeza de polpa podem ser parcialmente inibidas com aplicações de $\mathrm{GA}_{3}$ em pré-colheita. Segundo $\mathrm{PeCH}$ et al. (1994), o GA atua inibindo a ação de clorofilases e a produção de etileno, sendo desconhecido o mecanismo de ação e a forma de atuação nas vias bioquímicas.

Em pêssegos, Amarante et al. (2005) observaram efeito sinérgico entre o AVG e o $\mathrm{GA}_{3}$ no controle da maturação e na manutenção da qualidade de pêssegos armazenados sob frigoconservação. Assim, tratamentos à base de AVG, em combinação com $\mathrm{GA}_{3}$, podem representar grande potencial para utilizaçáo em pomares comerciais de ameixa. Isso pode retardar o ponto de colheita e prolongar o período de armazenamento, permitindo assim, maiores ganhos financeiros aos produtores. No entanto, ainda náo existem informaçóes sobre o efeito conjunto da aplicaçáo pré-colheita de AVG e GA 3 sobre a manutenção da qualidade de ameixas após o armazenamento. Assim, o objetivo deste trabalho, baseou-se na hipótese de que o uso isolado ou em combinação de AVG e GA, em pré-colheita, pode melhorar a manutenção da qualidade de ameixas 'Laetitia' após o armazenamento refrigerado. Espera-se esse resultado, devido à possibilidade dessas substâncias retardarem a maturação e o amadurecimento dos frutos, uma vez que inibem a rota de biossíntese de etileno (РеCH et al., 1994; Steffens et al., 2005a,b; Amarante et al., 2005).

\section{MATERIAL E MÉTODOS}

O experimento foi desenvolvido no ano agrícola de 2006/2007 com ameixeiras da cultivar Laetitia, em um pomar comercial, localizado no município de Lages (SC). Os frutos das plantas tratadas foram armazenados em câmara frigorífica comercial.

Os frutos utilizados no experimento foram colhidos em 25 de janeiro de 2007, 14 dias após o início da colheita comercial desta cultivar.

Os tratamentos consistiram na pulverização précolheita das plantas com AVG e GA, segundo esquema bifatorial, combinando três doses de AVG $(0,90$ e 120 $\left.\mathrm{mg} \mathrm{L}{ }^{-1}\right)$ com duas doses de $\mathrm{GA}_{3}\left(0\right.$ e $\left.100 \mathrm{mg} \mathrm{L}^{-1}\right)$. Foi utilizado pulverizador costal, com capacidade de $20 \mathrm{~L}$, adicionando-se a calda o espalhante adesivo Silwet $(0,01 \% \mathrm{v} / \mathrm{v})$, 
com aplicação até o ponto de escorrimento foliar. O AVG e o $\mathrm{GA}_{3}$ foram aplicados aos sete e 28 dias antes da colheita comercial dos frutos, respectivamente.

Utilizou-se o delineamento em blocos ao caso, e cada tratamento foi repetido quatro vezes. Cada repetição foi consituída por 10 plantas (tendo cada parcela seis plantas úteis e duas como bordadura em cada extremidade da fileira); de cada parcela foram colhidos 25 frutos, os quais foram submetidos ao armazenamento refrigerado (temperatura de $0,5 \pm 0,2{ }^{\circ} \mathrm{C}$ e UR de $92 \pm 2 \%$ ) por 22 dias e mais cinco dias de exposição dos frutos em condiçôes não controladas (temperatura média de $23 \pm 5^{\circ} \mathrm{C}$ e umidade relativa média de $60 \pm 5 \%$ ).

Após o armazenamento refrigerado mais cinco dias de exposição dos frutos nas condiçốes acima descritas, foram realizadas as determinaçóes de firmeza de polpa, atributos de textura (força para ruptura da epiderme, resitência da polpa a penetração e resistência do fruto à compressão), acidez titulável, sólidos solúveis e ocorrência de podridóes.

A firmeza de polpa foi determinada na regiáo equatorial dos frutos, em dois lados opostos, após a remoção de pequena porção da epiderme, com o auxílio de penetrômetro manual equipado com ponteira de $7,9 \mathrm{~mm}$ de diâmetro.

Os atributos de textura foram analisados com um texturômetro eletrônico TAXT-plus (Stable Micro Systems Ltd., Reino Unido), em termos de força necessária para o rompimento da epiderme, para a penetração na polpa e para a compressão do fruto inteiro. Para a quantificação da força necessária para o rompimento da epiderme e para a penetração na polpa, foi utilizada ponteira modelo PS2, com $2 \mathrm{~mm}$ de diâmetro, a qual foi introduzida na polpa a uma profundidade de $5 \mathrm{~mm}$ com velocidades pré-teste, teste e pós-teste de 30,5 e $30 \mathrm{~mm} \mathrm{~s}^{-1}$, respectivamente. A força para compressão do fruto foi determinada usandose uma ponteira modelo $\mathrm{P} / 75$, com $75 \mathrm{~mm}$ de diâmetro, que exerceu uma força de compressão até a deformação de $5 \mathrm{~mm}$ na superfície do fruto.

Os valores de acidez titulável foram determinados utilizando-se uma amostra de $10 \mathrm{~mL}$ de suco dos frutos, previamente extraído de fatias transversais retiradas da regiāo equatorial das ameixas e trituradas em uma centrífuga elétrica. Essa amostra foi diluída em $90 \mathrm{~mL}$ de água destilada e titulada com solução de hidróxido de sódio 0,1 $\mathrm{N}$ até $\mathrm{pH} 8,1$, sendo os resultados expressos em meq de ácido cítrico $100 \mathrm{~mL}^{-1}$.

Os teores de sólidos solúveis foram determinados por refratometria, utilizando-se o suco extraído conforme descrito para a acidez titulável, sendo realizada a correção do efeito da temperatura $\left(20^{\circ} \mathrm{C}\right)$ e os resultados expressos e ${ }^{\circ}$ Brix.

A ocorrência de podridóes foi avaliada pela contagem dos frutos afetados, interna e externamente, com lesóes maiores do que $5 \mathrm{~mm}$ de diâmetro e causadas por patógenos (STEFFens et al., 2005a).
Os dados foram submetidos à análise da variância (ANOVA). Dados em porcentagem foram transformados pela fórmula arco-seno $[(x+0,5) / 100]^{1 / 2}$ antes de serem submetidos à ANOVA. Para a comparação das médias, adotou-se o teste de Tukey $(\mathrm{p}<0,05)$.

\section{RESULTADOS E DISCUSSÃO}

Após 22 dias de armazenamento dos frutos a $0,5^{\circ} \mathrm{C}$ e mais cinco dias de exposição dos frutos em condição ambiente, não foi observada interação entre os tratamentos com $\mathrm{AVG}$ e $\mathrm{GA}_{3}$ para todos os atributos avaliados nos frutos .

A firmeza de polpa proporcionou maiores valores nos frutos dos tratamentos com AVG (90 e $120 \mathrm{mg} \mathrm{L}^{-1}$ ) (Figura 1A) e $\mathrm{GA}_{3}\left(100 \mathrm{mg} \mathrm{L}^{-1}\right)$ (Tabela 2), e o efeito do incremento nas doses de AVG propiciou efeito linear sobre a manutenção da firmeza de polpa. O efeito do AVG sobre a manutenção da firmeza de polpa também foi observado em maçãs (Steffens et al., 2005), pêssego (Amarante et al., 2005), nectarina (BYers, 1997) e caqui (Ferri et al., 2002). Amarante et al. (2005) também observaram maior firmeza de polpa em pêssegos tratados com $\mathrm{GA}_{3}$. A resposta da firmeza de polpa ao AVG está diretamente relacionada ao efeito sobre a reduçáo na síntese de etileno. O etileno é necessário para a promoção na atividade de enzimas responsáveis pela perda de firmeza de polpa (Johnston et al., 2001; Majumder e Mazumdar, 2002). Majumder e Mazumdar (2002) constataram que o aumento na atividade da enzima poligalacturonase foi altamente correlacionado à evolução de etileno. $\mathrm{O}$ mecanismo de ação do $\mathrm{GA}_{3}$ na manutenção da firmeza de polpa parece estar relacionado ao efeito na redução da produção de etileno, reduzindo assim a atividade de enzimas hidrolíticas de parede celular (РeCH et al., 1994; FERri et al., 2002).

A variável força para a ruptura da epiderme não representou diferença significativa entre os tratamentos avaliados (Tabela 1). Segundo Guillermin et al. (2006), pode ocorrer comportamento diferenciado entre a consistência da polpa e a resistência da epiderme, pois a resistência do

Tabela 1. Acidez titulável e incidência de podridóes em ameixas 'Laetitia' em função da aplicação pré-colheita com aminoetoxivinilglicina (AVG) após 22 dias de armazenamento mais cinco dias de exposição dos frutos em condição ambiente

\begin{tabular}{|c|c|c|}
\hline AVG & $\begin{array}{c}\text { Força para ruptura } \\
\text { da epiderme }(\mathrm{N})\end{array}$ & Acidez titulável \\
\hline $\mathrm{mg} \mathrm{L}^{-1}$ & & $\begin{array}{l}\text { meq de ácido cítrico } \\
\qquad 100 \mathrm{~mL}^{-1}\end{array}$ \\
\hline 0 & $1,19^{\text {ns }}$ & $20,22^{\text {ns }}$ \\
\hline 90 & 1,19 & 21,20 \\
\hline 120 & 1,10 & 20,20 \\
\hline C.V.(\%) & 14,0 & 7,7 \\
\hline
\end{tabular}

$\mathrm{ns}=$ regressão de $1^{\circ}$ grau não significativa. 

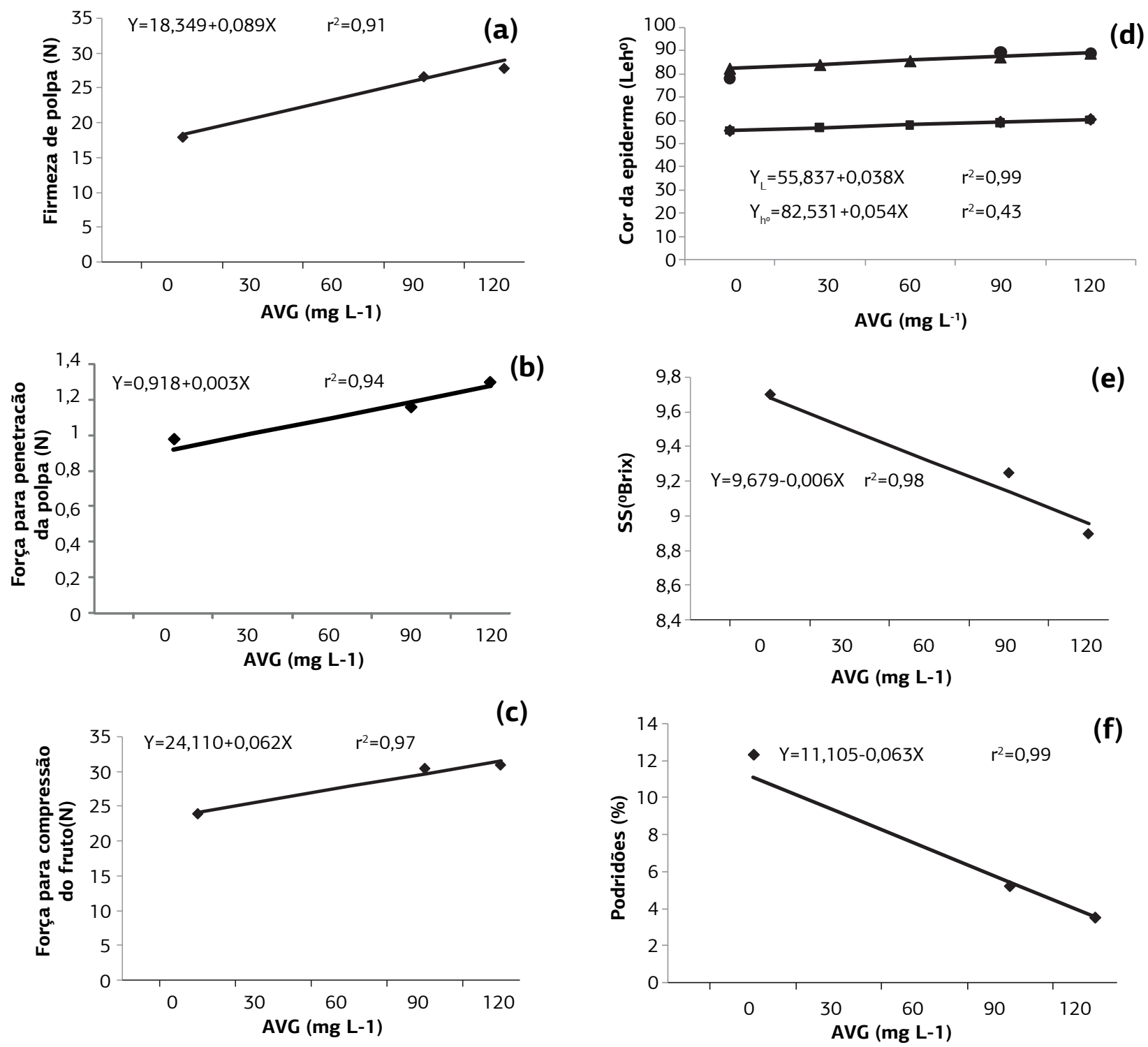

Figura 1. Firmeza de polpa (a), forças para penetração da polpa (b) e para compressão do fruto (c), cor da epiderme (L e hoo (d), sólidos solúveis (e) e ocorrência de podridōes (f) em função da aplicação pré-colheita com aminoetoxivinilglicina (AVG) após 22 dias de armazenamento mais cinco dias de exposiçáo dos frutos em condição ambiente. Cada símbolo representa o valor médio de oito amostras. Pontos e linhas contínuas referem-se a valores ajustados e observados respectivamente.

tecido epidérmico sofre menos variação com o avanço do amadurecimento, protegendo o tecido interno contra a desintegração das células.

As forças para compressão do fruto e para penetraçáo da polpa foram maiores nos frutos tratados com AVG (Figura 1 b,c) e $\mathrm{GA}_{3}$ (Tabela 2); o efeito do incremento nas doses de AVG proporcionou efeito linear sobre a manutenção desses atributos de textura. Esse resultado, bem como o observado com a avaliação da firmeza de polpa, evidencia o efeito dos tratamentos com AVG e GA no atraso do amadurecimento dos frutos, uma vez que a ameixa possui acentuada redução na consistência da polpa com a evoluçáo do amadurecimento.

A acidez titulável não foi influenciada pelo AVG (Tabela 1). Em maçãs 'Gala' a aplicação pré-colheita de
AVG também não influenciou a acidez titulável após o armazenamento dos frutos (STEFFENs et al., 2005). Ao que concerne ao $\mathrm{GA}_{3}$, na dosagem de $100 \mathrm{mg} \mathrm{L}^{-1}$, o mesmo corroborou para a manutenção da acidez titulável em níveis mais elevados (Tabela 3). Em pêssegos 'Rubidoux' o $\mathrm{GA}_{3}$ também manteve maior acidez titulável em frutos armazenados (Amarante et al., 2005). Contudo, em caqui 'Fuyu' náo foi observado efeito significativo do tratamento com $\mathrm{GA}_{3}$ sobre a manutenção da acidez titulável (Ferri et al., 2004). O fato de ter sido observado, no presente trabalho, efeito do $\mathrm{GA}_{3}$ sobre a manutençáo da acidez de ameixas 'Laetitia' e em caqui 'Fuyu' não ocorrer o mesmo efeito (FERRI et al., 2004), evidencia que a ação do $\mathrm{GA}_{3}$ sobre a manutenção da acidez dos frutos pode ser espécie-dependente. 
Tabela 2. Firmeza de polpa e atributos de textura em ameixas 'Laetitia' em função da aplicação pré-colheita com ácido giberélico (GA $)$ após 22 dias de armazenamento mais cinco dias de exposição dos frutos em condição ambiente

\begin{tabular}{lcccc}
$\mathbf{G A}_{3}$ & Firmeza de polpa (N) & $\begin{array}{c}\text { Força para ruptura } \\
\text { da epiderme }\end{array}$ & $\begin{array}{c}\text { Atributos de textura (N) } \\
\text { Força para penetração } \\
\text { da polpa }\end{array}$ & $\begin{array}{c}\text { Força para compressão } \\
\text { do fruto }\end{array}$ \\
\hline $\mathbf{m g ~ L} \mathbf{H}^{-1}$ & $20,90 \mathrm{~b}^{*}$ & $1,28 \mathrm{a}$ & $1,03 \mathrm{~b}$ & $24,60 \mathrm{~b}$ \\
\hline 0 & $28,20 \mathrm{a}$ & $1,24 \mathrm{a}$ & $1,27 \mathrm{a}$ & $32,20 \mathrm{a}$ \\
\hline 100 & 12,7 & 14,0 & 12,5 & 13,9 \\
\hline C.V. $(\%)$ & & & & \\
\hline
\end{tabular}

${ }^{*}$ Médias seguidas por mesma letra nas colunas não diferem entre si pelo peste Tukey $(\mathrm{p}<0,05)$.

Tabela 3. Cor da epiderme, acidez titulável, sólidos solúveis e incidência de podridões em ameixas 'Laetitia' em função da aplicação précolheita com ácido giberélico $\left(\mathrm{GA}_{3}\right)$ após 22 dias de armazenamento mais cinco dias de exposição dos frutos em condição ambiente

\begin{tabular}{|c|c|c|c|c|c|}
\hline \multirow[b]{2}{*}{$\mathrm{GA}_{3}$} & \multicolumn{2}{|c|}{ Cor da epiderme } & \multirow{2}{*}{ Acidez titulável } & \multirow{2}{*}{ Sólidos solúveis } & \multirow{2}{*}{ Podridões } \\
\hline & $\mathbf{L}$ & $\mathbf{h}^{\circ}$ & & & \\
\hline $\mathrm{mg} \mathrm{L}^{-1}$ & & & meq de ácido cítrico $100 \mathrm{~mL}^{-1}$ & ${ }^{\circ}$ Brix & $\%$ \\
\hline 0 & $58,60 a^{*}$ & $88,48 a$ & $19,40 b$ & $9,71 \mathrm{a}$ & $8,80 \mathrm{a}$ \\
\hline 100 & $58,45 a$ & $84,22 a$ & $21,07 a$ & $8,82 b$ & $4,56 a$ \\
\hline C.V. $(\%)$ & 4,6 & 6,2 & 7,7 & 7,6 & 55,6 \\
\hline
\end{tabular}

*Médias seguidas por mesma letra nas colunas não diferem entre si pelo peste Tukey $(\mathrm{p}<0,05)$.

Os teores de SS foram maiores nos frutos que não receberam aplicação pré-colheita de AVG (Figura 1e) e $\mathrm{GA}_{3}$ (Tabela 3), e à medida que se aumentou a dose de ambos houve reduçáo nos teores de SS. Possivelmente, os maiores valores de SS estáo relacionados com o maior conteúdo de pectinas solúveis, uma vez que estes frutos tiveram os menores valores de firmeza de polpa e menor resistência à compressão, demonstrando maior avanço no amadurecimento dos frutos do tratamento controle. Relaçáo inversa entre valores de firmeza de polpa e os teores de SS também foi observado em goiabas 'Pedro Sato' armazenadas sob refrigeração (STEFFens et al., 2008).

A cor da epiderme não foi influenciada pelo $\mathrm{GA}_{3}$ (Tabela 3), porém o AVG retardou linearmente a evolução da cor da epiderme com o incremento nas doses (maiores valores de $b^{\circ}$ e $L$ ) (Figura 1d). Resultados similares foram observados na colheita de ameixas 'Laetitia' tratadas com reguladores de crescimento (STEFFens et al., 2009). Como a mudança na cor durante o amadurecimento de ameixas é considerado processo dependente de etileno (Argenta et al., 2003), explica-se a menor intensidade de coloraçáo vermelha nos tratamentos com AVG. Todavia, segundo LÈLIEVRE et al. (1997), os processos envolvidos nas mudanças da cor podem ser dependentes ou independentes de etileno, de acordo com o tipo de pigmento envolvido e com a espécie de fruto. Dessa forma, o tratamento com $\mathrm{GA}_{3}$ também pode reduzir a intensidade de cor vermelha nos frutos devido ao efeito no retardo da maturação (Ferri et al., 2002 e 2004; Amarante et al., 2005), embora no presente trabalho não tenha sido observado efeito do $\mathrm{GA}_{3}$.

A ocorrência de podridóes foi menor com o incremento nas doses de AVG (Figura 1f). Em maçãs 'Gala' também foi observado menor ocorrência de podridóes após o armazenamento refrigerado, com a aplicação em pré-colheita de AVG (STEFfens et al., 2005). Esses autores citam que possivelmente frutos tratados com AVG havia menor incidência de podridóes, em virtude do estádio menos avançado de amadurecimento, uma vez que frutos imaturos são menos suscetíveis a podridôes do que frutos maduros (Wills et al., 1998). Segundo Brackmann e SAQuet (1995), frutos em estádios mais avançados de amadurecimento possuem pouca resistência à penetração, facilitando o desenvolvimento de patógenos.

\section{CONCLUSÕES}

1. A aplicação pré-colheita isolada de $\mathrm{AVG}$ e $\mathrm{GA}_{3}$ possibilita a preservação da qualidade de ameixas cultivar Laetitia durante o armazenamento refrigerado, contudo deve ser considerado a relaçáo custo-benefício do uso dessas substâncias.

2. O uso combinado desses dois reguladores não causa benefícios à preservação da qualidade de ameixas 'Laetitia'.

\section{AGRADECIMENTOS}

À empresa Fruticultura Pilati pela cessão de área para realização deste experimento. Também ao Conselho Nacional de Desenvolvimento Científico e Tecnológico (CNPq) e ao Programa de Bolsas de Iniciação Científica da Universidade do Estado de Santa Catarina pela concessão de Bolsas de Iniciação Científica e de Produtividade em Pesquisa. 


\section{REFERÊNCIAS}

AMARANTE, C.V.T. do; DREHMER, M.M.F.; SOUZA, F; FRANCESCATO, P. A pulverização pré-colheita com ácido giberélico $\left(\mathrm{GA}_{3}\right)$ e aminoetoxivinilglicina (AVG) retarda a maturação e reduz as perdas de frutos na cultura do pessegueiro. Revista Brasileira de Fruticultura, v.27, p.1-5, 2005.

ARGENTA, L.C.; KRAMMES, J.G.; MEGGUER, C.A.; AMARANTE, C.V.T.; MATTHEIS, J. Ripening and quality of 'Laetitia' plums following harvest and cold storage as affected by inhibition of ethylene action. Pesquisa Agropecuária Brasileira, v.38, p.1139-1148, 2003.

BRACKMANN, A.; MELLO, A.M.; FREITAS, S.T. Qualidade pós-colheita de caqui 'Kyoto', tratados com ácido giberélico e aminoetoxivinilglicina em pré-colheita. Revista da Faculdade de Zootecnia, Veterinária e Agronomia, v.9, p.48-55, 2002.

BRACKMANN, A.; SAQUET, A.A. Armazenamento de maçã cv. Gala em atmosfera controlada. Revista Brasileira de Agrociência, v.1, p.55-60, 1995.

BYERS, R.E. Peach and nectarine fruit softening following aminoethoxyvinylglycine sprays and dips. HortScience, v.32, p.8688, 1997.

FERRI, V.C.; RINALDI, M.M.; DANIELLI, R.; LUCHETTA, L.; ROMBALDI, C.V. Controle da maturação de caquis 'Fuyu', com o uso de aminoetoxivinilglicina e ácido giberélico. Revista Brasileira de Fruticultura, v.24, p.344-347, 2002.

FERRI, V.C.; RINALDI, M.M.; SILVA, J.A.; LUCHETTA, L.; MARINI, L.; ROMBALDI, C.V. Ácido giberélico no retardamento da maturação de caquis (Diospyrus kaki, L.) cultivar Fuyu. Ciência e Tecnologia dos Alimentos, v.24, p.1-5, 2004.

GUILLERMIN, P.; DUPONT, N.; LE MORVAN, C.; LE QUÉRÉ, J.M.; LANGLAIS, C.; MAUGET, J.C. Rheological and technological properties of two cider apple cultivars. LWT - Food Science and Technology, v.39, p.995-1000, 2006.

JOHNSTON, J.W.; HEWETT, E.W.; HERTOG, M.L.A.T.; HARKER, F.R. Temperature induces differential softening responses in apple cultivars. Postharvest Biology and Technology, v.23, p.185-196, 2001.
LELIÈVRE, J. M.; LATCHE, A.; JONES, B.; BOUZAYEN, M. Ethylene and fruit ripening. Physiologia Plantarum, v.101, p.727739, 1997.

MAJUMDER, K.; MAZUMDAR, B.C. Changes of pectic substances in developing fruits of cape-gooseberry (Physalis peruviana L.) in relation to the enzyme activity and evolution of ethylene. Scientia Horticulturae, v.96, p.91-101, 2002.

PECH, J.C.; LATCHÉ, A.; BALAGUÉ, C.; BOUZAYEN, M.; LELIÈVRE, J.M. Postharvest physiology of climateric fruits: recent development in the biosynthesis and action of ethylene. Sciencia Alimentaria, v.14, p.3-14, 1994.

PETRI, J.L.; LEITE, G.B.; LUNARDELLI, E. Efeito de aminoetoxivinilglicine (AVG) na maturaçáo de frutos de ameixeira. In: ENCONTRO NACIONAL DE FRUTICULTURA DE CLIMA TEMPERADO - ENFRUTE, 8., 2005, Fraiburgo. Anais... Caçador: EPAGRI, 2005. p.313-314.

STEFFENS, C.A.; GIEHL, R.F.H.; BRACKMANN, A. Maçã 'Gala' armazenada em atmosfera controlada e tratada com aminoetovinilglicina e ethephon. Pesquisa Agropecuária Brasileira, v.40, p.837-843, $2005 a$.

STEFFENS, C.A.; SESTARI, I.; BRACKMANN, A. Queda pré-colheita de maçâs 'Gala' e 'Fuji'com aminoetoxivinilglicina e ethephon. Revista Brasileira de Agrociência, v.11, p.329-332, 2005b.

STEFFENS, C.A.; AMARANTE, C.V.T.; SILVEIRA, J.P.G.; CHECHI, R.; ESPINDOLA, B.P. Tolerância ao dano pelo frio em goiabas 'Pedro Sato' submetidas ao condicionamento térmico. Biotemas, v.21, p.75-80, 2008.

STEFFENS, C.A.; AMARANTE, C.V.T. do; CHECHI, R.; SILVEIRA, J.P.G.; BRACKMANN, A. Aplicação pré-colheita de reguladores vegetais visando retardar a maturação de ameixas 'Laetitia'. Ciência Rural, v.39, p.1369-1373, 2009.

WILLS, R. H.; MCGLASSON, W. B.; GRAHAM, D.; JOYCE, D. Postharvest: an introduction to the physiology and handling of fruit, vegetables and ornamentals. 4 ed. New York: CAB International, 1998. $262 \mathrm{p}$. 